\title{
LES Computation on Spray Behavior of a Pintle Injector Nozzle
}

\author{
Palani Kumar Chidambaram¹, Ja Ye Koo², Heuy Dong Kim³ \\ ${ }^{1}$ FMTRC, Daejoo Machinery Co Ltd \\ 1028, Woram-Dong, Dalseo-Gu, Daegu, Korea. \\ kumar@djair.co.kr \\ ${ }^{2}$ Korea Aerospace University \\ Seoul, Korea. \\ jykoo@kau.ac.kr \\ ${ }^{3}$ Dept of Mechanical Engineering, Andong National University \\ Andong, Korea \\ kimhd@andong.kr
}

\section{Extended Abstract}

There is a renewed interest in using a pintle injector as the injection system of liquid rocket engines. This is mainly due to its advantages such as availability of single injector unit instead of several injector elements, low cost and ability for wide throttling along with a high efficiency. The pintle injector was developed originally over six decades ago from an experimental device that was used to study reaction rates of hypergolic propellants. Pintle injectors were also used in lunar exploration module (1969) and is currently being used by Space X and Northrop Grumman Aerospace Systems to develop a low-cost engine.

Unlike traditional coaxial injectors, the pintle injector has a complex distinctive shape because of its moving parts. Hence, the flow characteristics of the coaxial injector and the pintle injector are significantly different. This demands the need for fundamental understanding of the operation of pintle injectors. Experiments were carried out on moving pin type injector [1]. This was followed by numerical verifications in a two dimensional domain using standard turbulence models to compare spray angle, distributions of velocity, volume fraction of liquid and spray density [2]. While the velocity and liquid fraction contours matched well, there was a significant deviation in the spray angles for highly atomized conditions.

In the present work, three dimensional large eddy simulations (LES) are performed to compare and contrast the earlier numerical and experimental work. A 45 degree sector is chosen as the computational domain and fine mesh is generated with nearly 1 million cells. The basic flow equations of continuity, momentum and energy are selected as the governing equations and solved using a commercial solver. Multiphase model is enabled with air as gas phase and water as liquid phase. Input conditions are taken from the experiments. Simulations are first performed with standard k- $\omega$ model to develop the flow and later switched over to LES.

One disadvantage with LES is the excessively high mesh resolution requirement for wall boundary layers where the largest scales in the turbulence spectrum are geometrically very small. This requires very fine grid and small time steps for achieving accurate solutions. Thus LES is usually recommended for flows where boundary layers are either not relevant or laminar - that is, very few real life flows. Thus a wall modelled LES (WMLES) sub grid-scale model has become popular where the RANS portion of the model is activated in the inner part of the logarithmic boundary layer and outer part is covered by modified LES formulation. Such a model is applicable for a wide range of flows and is used in the present study. Based on the velocity field, the flow time is calculated to be about 2 milliseconds. The time step of the simulation is chosen as 1e$7 \mathrm{~s}$. The equations are iterated several times in a time step to attain convergence before progressing to the next time step. Simulations are performed for a physical time covering 2-3 flow times and time averaged data is extracted for validation of the numerical model.

\section{References}

[1] M. Son, K. J. Yu, J. Y. Koo, O. C. Kwon, and J. S. Kim, "Effects of Momentum Ratio and Weber Number on Spray Half Angles of Liquid Controlled Pintle Injector," Journal of Thermal Science, vol. 24, no. 1, pp. 37-43, 2015. 
[2] C. G. Yue, X. L. Chang, S. J. Yang, and Y. H. Zhang, "Numerical Simulation of a Pintle Variable Thrust Rocket Engine," Communications in Computer and Information Science, vol. 159, pp. 477-481, 2011. 